\title{
EVALUASI PROGRAM PENDIDIKAN KESETARAAN PAKET C VOKASIONAL DI PUSAT KEGIATAN BELAJAR MASYARAKAT (PKBM) BHINA SWAKARYA KABUPATEN BANDUNG (Aplikasi Evaluasi Program model Hammond)
}

\author{
Angelia Agustina \\ PKBM Sekolah Tunas Indonesia
}

Yetti Supriyati

FMIPA Universitas Negeri Jakarta

\begin{abstract}
The purpose of thi study was to evaluate the implementation of the Vocational $C$ Packege Program. Which is focused on the center of community learning activities (PKBM) located in Bhina Swakarya Kabupaten Bandung. This evaluation activity is expected to ccontribute to the improvement and refinement of the program and input to the program organizers in making decisions regarding efforts to improve program quality and effectiveness. The subjects of this study were learning residents, tutors, instituation, families, supervisor, and administrators. Data collection techniques using observation, interviews, documentation, and questionnaires. The results of the evaluation indicate that the implementation of the Vocational C Package program runs well but facilities and prasarana (facilities) is still lacking. The impact of Voational $C$ program package in PKBM Bhina Swakarya Kabupaten City Bandung on the implementation of compter vocational program has a very good on the citixen of learning.
\end{abstract}

Keywords: Paket C Vokasional, PKBM, Hammond modell

\begin{abstract}
ABSTRAK
Tujuan dari penelitian ini adalah untuk mengevaluasi pelaksanaan program paket C Vokasional. Yang difokuskan pada pusat kegiatan belajar masyarakat (PKBM) yang berada di Bhina Swakarya Kabupaten Bandung. Kegiatan evaluasi ini diharapkan dapat memberikan kontribusi untuk perbaikan dan penyempurnaan program tersebut dan masukan bagi penyelenggara program dalam membuat keputusan mengenai upaya-upaya peningkatan kualitas dan efektivitas program. Subyek penelitiannya adalah warga belajar, tutor, lembaga, keluarga, pengawas, dan administrator. Teknik pengambilan data menggunakan observasi, wawancara, dokumentasi dan kuesioner. Hasil evaluasi menunjukkan bahwa pelaksanaan program paket $C$ Vokasional berjalan baik tetapi sarana dan prasarana (fasilitas) masih kurang. Dampak Program Paket C Vokasional di PKBM Bhina Swakarya Kabupaten Bandung pada pelaksanaan program voksaional komputer (TIK) berdampak baik sekali pada warga belajar.
\end{abstract}

Kata Kunci: Paket C Vokasional, PKBM, Hammond model

\author{
Alamat Korespondensi \\ Pondok bahar JI Semeru II blok DD \\ No 16. Kota Tangerang \\ e-mail: \\ angelia2lagustina@gmail.com
}

\section{Pendahuluan}

Program Pendidikan Kesetaraan yang terdiri dari Paket A setara SD/MI dan Paket B setara SMP/MTs, serta Program Pendidikan Paket C setara SMA. Hal ini ditegaskan pada UndangUndang Nomor 20 tahun 2003 tentang Sistem Pendidikan Nasional yaitu "Pendidikan Nonformal diselenggarakan bagi warga masyarakat yang memerlukan layanan pendidikan yang berfungsi sebagai penganti, penambah, pelengkap pendidikan formal untuk mendukung pendidikan sepanjang hayat”. Pada bagian lain juga dikatakan "Hasil pendidikan nonformal adalah setara dengan hasil pendidikan formal yaitu melalui proses 
penilaian penyetaraan oleh lembaga dengan mengacu pada standar nasional pendidikan".

Pada tahun 2004 peserta didik paket C ada sebanyak 84.593 orang, pada tahun 2008 meningkat menjadi 606.310 orang. Pada tahun 2015 ada sebanyak 17,9 juta orang yang menjadi target dari Program Indonesia Pintar (PIP). Diantaranya meliputi peserta didik pada tingkat SD/MI/Paket A, SMP/MTS/Paket B, dan SMA/SMK/MA/Paket C. Untuk mensukseskan layanan program Pendidikan Kesetaraan Paket C pemerintah akan menyediakan bantuan sejumlah dana yang akan digunakan oleh pimpinan lembaga atau organisasi atau satuan pendidikan nonformal sebagai penyelenggara program pendidikan kesetaraan didaerah.

Apabila dilihat dari mutu, tingkat kelulusan Ujian Nasional Pendidikan Kesetaraan Paket C rata-rata $76,40 \%$ (IPS) dan 68\% (IPA) pada tahun 2007 dan hal ini relative konstan terjadi pada tahun 2008 dan 2009. Berdasarkan gambaran diatas kebijakan penyelenggaraan paket $C$ tahun 2009 agar lebih bermutu dan relevan dengan kebutuhan masyarakat.

Paket C Vokasional diperuntukkan bagi peserta dididk yang ingin meningkatkan kompetensinya sebagai bekal bekerja di sector formal dan informal. Lulusan Paket $C$ tidak hanya berorientasi pada ijazah tapi yang tidak kalah pentingnya adalah bahwa lulusan Paket $\mathrm{C}$ memiliki kompetensi keterampilan yang dapat digunakan sebagai bekal mencari nafkah serta pengurangan jumlah peserta didik dari rata-rata kelompok besar 40 orang menjadi 30 orang utamanya untuk kelas awal dan kelas lanjutan satu.

Pendidikan kesetaraan Program Pendidikan Kesetaraan Paket C Vokasional. Program ini ditujukan untuk memberikan layanan pendidikan menengah yang terintegrasi dengan keterampilan yang terstruktur sehingga lulusan Program Pendidikan Kesetaraan Paket C Vokasional memiliki kompetensi yang dapat dijadikan bekal untuk melakukan usaha mandiri atau bekerja kepada orang lain.

Program pendidikan keseraan perlu terus dikembangkan, dengan sejalannya tuntutan perkembangan kebutuhan masyarakat dan untuk meningkatkan mutu sumberdaya manusia, serta dengan sejalannya kebijakan Kementerian Pendidikan dan Kebudayaan sejak tahun 2015 mengembalikan program pendidikan kesetaraan kepada Direktorat Jenderal Pendidikan Anak Usia Dini dan Pendidikan Masyarakat Pengambangan program pendidikan kesetaraan dapat dilakukan melalui pengembangan yang berorientasi pada pemberdayaan potensi peserta didik dengan mengoptimalkan kemampuan peningkatan pengetahuan dan keterampilan fungsional serta keperibadian yang professional.

Secara umum tujuan dari penelitian ini adalah untuk mengevaluasi pelaksanaan program paket $C$ Vokasional pada PKBM Bhina Swakarya Kabupaten Kota Bandung. Yang difokuskan pada Input, Proses, Output dan Outcome dari program tersebut. Kegiatan evalusi ini diharapkan dapat memberikan kontribusi untuk perbaikan dan penyempurnaan program tersebut dan masukan bagi penyelenggara program dalam membuat keputusan mengenai upaya-upaya peningkatan kualitas dan efektifitas program. Secara spesifik tujuan penelitian sebagai berikut:

a. Intruction (Instruksi)

Adalah upaya untuk mengetahui karakteristik dari pelaksanaan program paket $C$ Vokasional yang terdiri dari:

I) Organization meliputu tujuan, visi dan misi lembaga dan keselarasan dengan tujuan dasar pendidikan.

2) Content meliputu bahan ajar, media pembelajaran, materi pembelajaran dan strategi pembelajaran

3) Method meliputi metode pembelajaran

4) Facilities meliputi sarana dan prasana pembelajaran

5) Cost meliputi biaya

b. Population (Populasi)

Adalah upaya untuk mengetahui karakteristik dari pelaksanaan program paket $C$ Vokasional yang terdiri dari:

I) Teacher meliputi tutor yang menjadi kekuatan untuk mempengaruhi keberhasilan program paket $C$ Vokasional.

2) Student meliputi warga belajar yang memiliki motivasi yang tinggi dan dapat mengembangkan dan menggali potensi yang dimiliki pada dirinya.

3) Administrator yaitu orang administrasi yang dapat memberikan pelayanan yang baik bagi tutor, warga belajar dan masyarakat sekitar. 
4) Educational Spesialist yaitu spesialis pendidikan (Pengawas pendidikan), dapat memberikan pengarahan kepada tutor dan lembaga agar dapat mensukseskan program tersebut.

5) Family yaitu keluarga yang dapat mendukung dan memberikan motivasi kepada warga belajar dan masyarakat sekitar agar dapat mensukseskan program paket C Vokasional.

6) Community yaitu komunitas PKBM yang berada disekitar wilayah kabupaten kota Bandung yang dapat memberikan motivasi, wawasan dan memberikan motivasi kepada warga belajar, tutor dan lembaga agar dapat mensukseskan program paket C Vokasional.

c. Behavior (Perilaku)

Adalah upaya untuk mengetahui karakteristik dari pelaksanaan program paket $C$ Vokasional yang terdiri dari:

I) Affective yaitu warga belajar dapat meningkatkan sikap keterampilan terhadap program paket $\mathrm{C}$ Vokasional.

2) Psychomotor yaitu warga belajar dapat mengembangkan keterampilan dan keahlian dan dapat mengembangkan keahlian serta dapat meningkatkan taraf perekonomian.

3) Cognitive yaitu warga belajar mampu membaca dan memahami konsep teori dari program vokasional yang diberikan pada PKBM Bhina Swakarya.

Penelitian evaluasi ini diharapkan dapat bermanfaat bagi tutor dan lembaga, yaitu dapat memahami dan mengimplementasikan evaluasi program pelaksanaan pembelajaran unggulan dalam rangka meningkatkan mutu pendidikan khususnya di PKBM Bhina Swakarya dan PKBM lain pada umumnya. Hasil penelitian ini diharapkan bermanfaat sebagai rujukan bagi guru dalam melakukan evaluasi program sebagai rujukan bagi tutor dan lembaga dalam melakukan evaluasi program sebagai evaluasi pelaksanaan program yang dilakukan tenaga pendidik dan tenaga kependidikan secara maksimal.

Hasil penelitian ini diharapkan dapat berguna bagi peneliti dalam memperoleh informasi mengenai pelaksanaan program pendidikan kesetaraan paket $C$ vokasional pada PKBM Bhina
Swakarya Bandung dan sebagai kegiatan ilmiah yang menghasilkan data-data dari aspek-aspek yang dievaluasi sehingga hasil penelitian ini bisa dapat dipergunakan oleh pengambil kebijakan dalam membuat keputusan terhadap efektifitas dan kualitas dari program pendidikan kesetaraan paket $C$ vokasional yang dilakukan oleh PKBM Bhina Swakarya Bandung.

\section{Metode Penelitian}

Pendekatan dalam penelitian ini menggunakan model Hammond. Dasar kegiatan dalam evaluasi pengajaran pada program pendidikan kesetaraan Paket $C$ vokasional melalui tahapan menentukan tujuan, memutuskan desain yang tepat, memilih alat ukur, mengidentifikasi sumber data, menganalisa data, membuat kesimpulan. Pada tahapan diatas dapat dimuat dalam 3 tahapan yaitu Instruction, Population, Behavior:

a. Efektifitas dan kesesuaian Instruction pada program Paket C vokasional yang berhubungan dengan Organization, Content, Method dan Facilities.

b. Gambaran masalah yang berkaitan dengan substansi Population yang meliputi komponen a) teacher, b) student, c) instruction, d) educational, e) family, f) community

c. Kesesuaian behavior program Paket C vokasional. Berhubungan dengan hasil atau tujuan pembelajaran yang didasarkan pada a) cognitive domain, b) affective domain, c) psychomotor peserta program Paket C vokasional.

Data yang digunakan dalam penelitian ini bersumber dari data primer dan data sekunder. Data primer yaitu data yang langsung berasal dari sumber data (warga belajar) yang menjadi responden serta tutor, dan tokoh masyarakat. Sedangkan data sekunder adalah data yang nantinya akan diambil dari data yang sudah ada, yaitu berupa kebijakan, petunjuk operasional serta kriteria atau standarisasi penyelenggaraan program.

Pengumpulan data dalam peneltian ini dilaksanakan melalui beberapa instrument penelitian seperti wawancara, observasi, analisis dokumentasi dan angket. Untuk memperoleh data yang akurat, diperlukan alat pengumpul data yang dapat dipertanggung jawabkan secara valid dan reliable. Validitas menunjukkan pada kepastian 
atau ketelitian dan ketepatan alat ukur. Artinya sejauh mana alat ukur itu betul-betul tepat mengukur apa yang harusnya diukur. Sedangkan reliabilitas menunjukan konsistensi penggunaan alat ukur ini digunakan tetapi menunjukkan hasil yang sama.

Alat untuk pengumpulan data yang digunakan dalam penelitian evaluasi ini adalah: pedoman observasi, pedoman wawancara, analisis dokumentasi dan pedoman angket.

Pedoman observasi hanya digunakan sebagai teknik pengumpulan data penelitian evaluasi program pendidikan kesetaraan Paket C vokasional dengan komponen-komponen yang akan dievaluasi. Teknik wawancara digunakan sebagai teknik pengumpulan data dengan cara komunikasi langsung dengan narasumber atau responden yang berhubungan dengan program pendidikan kesetaraan Paket C Vokasional. Analisis dokumentasi yakni peneliti mengambil dokumen yang berhubungan dengan komponen yang berhubungan dengan komponen yang dibutuhkan dalam evaluasi.

Angket digunakan sebagai alat yang digunakan untuk pengumpul data secara tertulis yang terdiri dari daftar oertanyaan dan pernyataan yang disusun secara khusus dan digunakan untuk mencari informasi dan mendapatkan informasi yang benar dan akurat sesuai dengan komponen evaluasi yang akan dianalisis dalam penggunaan semua alat ukur atau alat pengumpulan data karena hal ini saling mendukung dan mendekati dalam penelitian.

\section{Hasil Penelitian dan Pembahasan}

Pembahasan program dalam penelitian ini membandingkan hasil temuan dengan kriteria evaluasi, sebagaimana model evaluasi yang digunakan yakni Hammond maka pembahasan akan diuraikan berdasarkan kriteria evaluasi.

Sehubungan dengan hal tersebut pembahasan dilakukan dengan membahas setiap komponen program kemudian dideskripsikan sesuai dengan kriteria evaluasi tersebut.

berikut:

\section{Intoduction}

\section{a. Organisasi (Tujuan, Visi dan Misi)}

Berdasarkan data hasil temuan dilapangan bahwa tujuan, visi dan misi yang terdapat pada PKBM Bhina Swakarya telah sesuai dengan tujuan, visi dan misi dasar program paket C Vokasional.

b. Content (Bahan ajar, Media pembelajaran dan Sumber belajar)

Berdasarkan hasil penelitian dilapangan ditemukan bahwa bahan ajar, media pembelajaran dan sumber belajar yang diberikan untuk warga belajar telah sesuai dengan kebutuhan warga belajar dan telah mengacu pada kurikulum dan silabus yang telah ditetapkan oleh pemerintah.

c. Methode

\section{Pembelajaran)}

(Pendekatan

Berdasarkan hasil penelitian dilapangan metode pembelajaran yang digunakan adalah ceramah, praktek dan bermain peran.

d. Facility (Sarana dan Prasarana)

Berdasarkan hasil penelitian dilapangan sarana dan prasarana yang terdapat pada PKBM Bhina Swakarya sudah baik dan menunjang proses pembelajaran. Namun masih ada yang kurang dari sarana dan fasilitas yaitu masih kurangnya komputer untuk warga belajar.

e. Cost (Biaya)

Berdasrkan temuan dilapangan lembaga PKBM dapat mengelola dan membuat laporan keuangan dengan baik.

\section{Instruction}

\section{a. Teacher (Tutor)}

Berdasarkan temuan dilapangan bahwa tutor yang mengajar di PKBM Bhina Swakarya adalah para tutor yang sudah berpengalaman yaitu dengan pendidikan terakhir adalah sarjana kependidikan.

\section{b. Student (Warga Belajar)}

Berdasarkan hasil temuan dilapangan bahwa warga belajar yang mengikuti program paket C Vokasional kebanyakan berusia diatas 20 tahun.

c. Administrator

Berdasarkan temuan dilapangan bahwa administrator sangat membantu warga belajar, tutor dan lembaga pada proses pembealajaran ataupun tidak.

\section{d. Educational Spesialist}

Berdasarkan hasil penelitian dilapangan ditemukan bahwa Educational spesialist 
yaitu pengawas atau penilik yang berasal dari dinas pusat daerah kabupaten kota Bandung.

\section{e. Family (Keluarga)}

Pada penelitian ini didapatkan bahwa keluarga sangat memiliki dampak yang sangat penting dalam meningkatkan motivasi warga belajar.

\section{Behavior}

\section{a. Afektif}

Berdasarkan hasil penelitian maka ditemukan bahwa sikap keterampilan warga belajar meningkat setelah mengikuti program paket C Vokasional.

\section{b. Psikomotor}

Berdasarkan hasil penelitian ditemukan bahwa adanya peningkatan pengembangan kemampuan komputer yang dimiliki warga belajar.

\section{c. Kognitif}

Berdasarkan hasil penelitian ditemukan bahwa hasil pengetahuan warga belajar tentang konsep materi komputer termasuk dalam kategori baik. Namun ada beberapa warga belajar yang masuk kedalam kategori cukup baik. Hal ini dapat dibuktikan dengan nilai kognitif yang didapatkan warga belajar.

\section{Kesimpulan}

Berdasarkan penelitian dan pembahasan dapat ditarik beberapa kesimpulan sebagai berikut:

\section{a. Introduction}

I) Organization program paket $C$ Vokasional dapat tercapai dan sesuai dengan kebijakan pemerintah. Tujuan, Visi dan Misi PKBM Bhina Swakarya sesuai dengan tujuan, Visi dan Misi pendidikan nonformal. Yaitu mewujudkan masyarakat yang terampil dan memiliki pengetahuan serta siap dalam dunia pekerjaan. Pelaksanaan Program, Bantuan Paket C Vokasional, dimana jumlah bantuan Paket $C$ Vokasional yang diterima telah dipergunakan untuk peruntukan pembelajaan sesuai komponen yang dibiaya seperti yang tertera dalam juknis. Semua sarana administrasi lembaga dalam penyelenggaran program paket $C$ sudah terpenuhi, diantaranya buku induk warga belajar, daftar hadir warga belajar, dan daftar hadir tutor, serta bahan ajar.

2) Content (bahan ajar, materi dan strategi pembelajaran) telah sesuai dan cocok untuk dipakai oleh warga belajar. Bahan ajar dibuat oleh para tutor dengan memilih materi pembelajaran yang sesuai dnega warga belajar dan cocok untuk diaplikasikan kepada dunia pekerjaan. Materi yang disajikan oleh tutor sangat baik dan simple sehingga warga belajar dapat dengan mudah mengingat dan mengaplikasikannya dalam kehidupan. sehari-hari. Strategi pembelajaran yang digunakan tutor sudah cukup baik, namun masih harus banyak diperbaiki, Karena strategi pembelajaran yang digunakan monoton dan kurang kreatif hal ini dapat berdampak pada warga belajar yang mudah merasa bosan.

3) Method (metode pembelajaran) yang digunakan tutor sangat baik dan dapat membuat warga belajar mudah mempelajari materi dan dapat mengingat materi pembelajaran dengan baik.

4) Facilities (sarana dan prasana) pada PKBM Bhina Swakarya sudah baik dan lengkap. Tersedianya ruang belajar yang cukup, dan fasilitas pendukung pembelajaran sudah tersedia baik, dan juga perawatan fasilitas pembelajaran sangat baik. Sehingga warga belajar dapat merasa nyaman untuk belajar diPKBM Bhina Swakarya. Namun berdasarkan temuan dilapangan dengan bertambahnya warga belajar yang ingin mengikuti program paket $C$ Vokasional maka akan berkurangnya ruang belajar. Juga kurangnya ketersediaan komputer untuk mendukung proses pembelajaran Vokasional komputer. Masih terdapatnya proses pembelajaran dilaksanakan yang dilaksanakan di luar sekretariat dengan menumpang. Kondisi tempat pembelajaran yang sudah cukup memadai. Proses pembelajaran yang dilaksanakan dalam program paket $C$ Vokasional ini telah berlangsung dengan baik. Telah melakukan evaluasi sebagai dasar dalam pengambilan keputusan dalam proses pembelajaran paket $C$ Vokasional. Tindak lanjut dari 
program ini dengan terciptanya lapangan usaha sendiri di rumah.

\section{b. Population}

I) Perekrutan Tutor Rata-rata pendidikan tutor adalah SI pendidikan dengan latar belakang pekerjaan adalah guru. Masih minimnya pelatihan yang diikuti oleh tutor. Proses Pembelajaran Proses pembelajaran yang telah mengacu pada pada SKL, KI, $K D$ dengan dasar acuan penentuan SKL, Kompetensi inti, dan Kompetensi Dasar, disusun berdasarkan berdasarkan kurikulumPendidikan KD Dit.Bindiktara. Tutor telah memiliki pedoman pembelajaran/penyelenggaraan program paket C Vokasional, memiliki silabus dan RPP, melakukan identifikasi kebutuhan belajar, memiliki jadwal pembelajaran, memiliki bahan dan sumber belajar (cetak dan non cetak)vokasi, memiliki instrumen penilaian, dan melakukan penyusunan modul/bahan ajar.

Pelaksanaan Kegiatan: Penggunaan jenis media pembelajaran yang digunakan yang bervariasi antara visual, dan audio visual. Terdapatnya strategi pembelajaran expository (penjelasan) dan discovery (penemuan) dengan berpusat pada warga belajar. Variasi metode pembelajaran yang digunakan ceramah, diskusi, main peran, dan praktik. Telah dibuatnya laporan perkembangan kemajuan pembelajaran warga belajar.

Pelaksanaan Program, Bantuan Paket C Vokasional, dimana jumlah bantuan Paket C Vokasional yang diterima telah dipergunakan untuk peruntukan pembelajaan sesuai komponen yang dibiaya seperti yang tertera dalam juknis. Semua sarana administrasi lembaga dalam penyelenggaran program paket $C$ sudah terpenuhi, diantaranya buku induk warga belajar, daftar hadir warga belajar, dan daftar hadir tutor, serta bahan ajar.

I) Sarana dan Prasarana: Masih terdapatnya proses pembelajaran dilaksanakan yang dilaksanakan di luar sekretariat dengan menumpang. Kondisi tempat pembelajaran yang sudah cukup memadai. Proses pembelajaran yang dilaksanakan dalam program paket C Vokasional ini telah berlangsung dengan baik. Telah melakukan evaluasi sebagai dasar dalam pengambilan keputusan dalam proses pembelajaran paket C Vokasional. Tindak lanjut dari program ini dengan terciptanya lapangan usaha sendiri di rumah.

2) Rata-rata warga belajar yang mengikuti pendidikan paket $C$ Vokasional atas kemauan sendiri, yang lain di ajak oleh lembaga. Tujuan Saudara mengikuti Paket C Vokasional, sebagian besar ingin terampil, dan lainnya ingin memperoleh ijazah. Rata-rata warga belajar telah memiliki bahan belajar/modul pelajaran Paket C Vokasional, untuk keterampilan yang dipelajarinya

Keterampilan: Telah sesuainya keterampilan yang diajarkan yang sesuai dengan keinginan warga belajar. Rata-rata warga belajar ingin mengembangkan sendiri keterampilan di rumah sebagai bekal usaha yang dapat memberi penghasilan ekonomi (uang).

Telah terpenuhinya perkembangan keterampilannya saat ini, yang dapat dijadikan usaha keluarga.

Hasil Belajar: Pengetahuan diakhir pelatihan, saudara di tes keterampilan yang diketahui telah mencapai standar kompetensi Rata-rata warga belajar telah menerima sertifikat keterampilan.

3) Sarana dan Prasarana: Masih terdapatnya proses pembelajaran dilaksanakan yang dilaksanakan di luar sekretariat dengan menumpang. Kondisi tempat pembelajaran yang sudah cukup memadai. Proses pembelajaran yang dilaksanakan dalam program paket $C$ Vokasional ini telah berlangsung dengan baik. Telah melakukan evaluasi sebagai dasar dalam pengambilan keputusan dalam proses pembelajaran paket $C$ Vokasional. Tindak lanjut dari program ini dengan terciptanya lapangan usaha sendiri di rumah.

\section{c. Behavior}

I) Motivasi Peserta Didik Rata-rata warga belajar yang mengikuti pendidikan paket $C$ Vokasional atas kemauan sendiri, yang lain 
di ajak oleh lembaga. Tujuan Saudara mengikuti Paket C Vokasional, sebagian besar ingin terampil, dan lainnya ingin memperoleh ijazah.

2) Keterampilan Telah sesuainya keterampilan yang diajarkan yang sesuai dengan keinginan warga belajar.

3) Hasil Belajar Pengetahuan diakhir pelatihan, saudara di tes keterampilan yang diketahui telah mencapai standar kompetensi.

\section{Rekomendasi}

a. Introduction

I) Perlu penambahan ruangan pembelajaran dan komputer.

2) Memberi saran kepada lembaga agar barangbarang yang sudah dibeli dimanfaatkan secara optimal sesuai peruntuksnnya.

3) Kurikulum yang digunakan perlu menjadikan warga belajar yang kreatif, aktif, inovatif, memiliki kecerdasan relegi, intelektual, mandiri serta karakter yang baik.

4) Perlu pengadaan media pembelajaran sehingga guru dapat menggunakan berbagai media dan sumber belajar.

5) Direktorat membuat standar harga barang dapat dijadikan sebagai lembaga untuk melakukan pembelian barang.

6) Memastikan pembelian barang-barang sarana PKBM sesuai dengan spesifikasi barang dan harga yang disesuaikan dengan proposal yang diajukan oleh lembaga penerima.

b. Population

I) Perlu pemanfaatan teknologi informasi dan komunikasi untuk kepentingan penyelenggaraan kegiatan pengembangan yang mendidik.

2) Perlu ada tenaga adminstrasi sehingga tutor merangkap menjadi tenaga administrasi.

3) Perlu melakukan sosialisasi sehingga warga belajar tidak hanya terfokus pada daerah setempat.

4) Kepada pengelola Paket C Vokasional untuk memperhatikan hal-hal yang masih belum dilaksanakan khususnya kehadiran warga belajar, keterampilan yang diajarkan agar sesuai dengan keinginan warga belajar

c. Behavior

Tutor perlu meningkatkan kemampuan warga belajar dalam keahlian vokasional.

\section{Daftar Pustaka}

Napitupulu WA. (2002). Guru dan Mutu Pendidikan" Makalah Loka Karya. Bali

Slamet. (1991). Belajar dan Faktor-Faktor yang Mempengaruhi. Jakarta: Rineka Cipta.

Djaali. (20I3). Psikologi Pendidikan. Jakarta: PT Bumi Aksara.

Arikunto, Suharsimi, (2013). Prosedur Penelitian Suatu Pendekatan Praktek. Jakarta: PT. Rineka Cipta.

Sudjana. (2004). Teknik Analisis Regresi dan Korelasi Bagi Para Peneliti. Bandung: PT Tarsito.

Djaali dan Muljono, Pudji. (2008). Pengukuran dalam Bidang Pendidikan. Jakarta: PPs UNJ.

Fahroni, Dedy. (20I5). Evaluasi Program Kepengawasan SMA di Kabupaten Ketapang Provinsi Kalimantan Barat. Tesis, Universitas Negeri Jakarta.

Hasan, Hamid. (2008). Evaluasi Kurikulum. Bandung: UPI \& Remaja Rosdakarya.

Jody L. Fitzpatrick, James S. Sanders dan Blaine R. Worthen. (2004). Program Evaluation Alternative Approach and Practical Guidelines. New York: Pearson Education.

Marvin C. Alkin (ed.). (2004). Evaluation Roots: Tracing Theorists View and Influences. London: Sage Publications.

Kementerian Pendidikan Nasional. (20I2). Buku Kerja Pengawas Sekolah. Jakarta.

Stufflebeam, Daniel L and L. S. Coryn, Chris. (20I4). Evaluation Theory, Models, \& Application. San Fransisco: Jossey-Base.

Ma'mur Asmani, (20I I). Jamal. Tuntunan Lengkap Metodologi Praktis Penelitian Pendidikan. Yogyakata: Diva Press. 
Suharsimi Arikunto. (2010). Evaluasi Program Pendidikan, Jakarta: Bumi aksara.

Anas Sudijono. (2007). Pengantar Evalusai Pendidikan. Jakarta: PT Raja Grafindo Persada.
Saburi Musa. (2005). Evaluasi Program Pembelajaran Dan Pemberdayaan Masyarakat. Bandung: Y-Pin Indonesia.

S. Naga, Dali. (2013). Teori Sekor pada Pengukuran Mental. Jakarta: PT. Nagarani Citrayasa. 